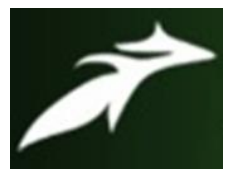

Chitrasena Padhy et al, International Journal of Advances in Agricultural Science and Technology,

Vol.7 Issue.12, December-2020, pg. 110-115

ISSN: 2348-1358

Impact Factor: 6.057

NAAS Rating: 3.77

\title{
Farmers' Psycho-Social Stress and Its Management
}

\section{Chitrasena Padhy' ${ }^{1}$ Pakalpati Satyanarayana Raju²; Rabindra Kumar Raj ${ }^{3}$; Kalee Prasanna Pattanayak ${ }^{4}$}

${ }^{1}$ Assistant Professor/Ph. D student, Department of Agricultural Extension, M.S. Swaminathan School of Agriculture, Centurion University of Technology and Management, Odisha, India

${ }^{2}$ Professor Emeritus, M.S. Swaminathan School of Agriculture, Centurion University of Technology and Management, Odisha, India

${ }^{3}$ Professor, Siksha 'O' Anusandhan (Deemed University), Bhubaneswar, Odisha, India

${ }^{4}$ Assistant Professor, School of Management, Centurion University of Technology and Management, Odisha, India

${ }^{1}$ chitrasenapadhy@cutm.ac.in $;{ }^{2}$ profraju@ cutm.ac.in; ${ }^{3}$ raj_rabindra@rediffmail.com; ${ }^{4}$ kaleeprasanna@cutm.ac.in

DOI: 10.47856/ijaast.2020.v07i12.015

Abstract: Modern day farming brings lot of stresses to farmers and farming communities. Farmers are affected by various types of mental issues. They are affected by time and financial pressure, weather uncertainty, market regulations, work unpredictability. When the pressures resulting in farming are beyond their control, farmers get frustrated. The effects of stress may be manifested in the form of mood swings, anxiety, change in sleep patterns, changes in appetite, fatigue, loss of interest in family, friends and hobbies, dependence on alcohol. Stress can affect family and social life. Agribusiness professionals should play a key role in helping mental health specialists find the reasons underlying farming stress. Farmers should be made aware of the physical, behavioural, emotional and cognitive symptoms of stress. Farmers should avoid unnecessary stress by learning how to say 'no', altering the stress situation, adapting to stressor by changing self, trying not to control the uncontrollable, spending time with family, going for a task. Farmers should be connected to well-wishing and close people, aware of people around them, do regular physical exercises, develop new interests, and show kindness and do good deeds for someone in need.

Keywords: Modern day farming, mental issues, financial pressure, anxiety, social life, physical exercises

\section{Introduction}

Factors such as weather extremes, market fluctuations and regulation changes make farm life more stressful. These stressors are on the top of every day risks the farmers face. The Bureau of Labour Statistics found farming among the ten occupations with most fatalities in the United States, with nearly 25 fatal injuries per 100,000 workers in 2018 ( Braverma, 2019; Hightower, 2020). The pressures occurring in agricultural industry are unique and beyond a person's control, that can be difficult and lead to feelings of frustration as reported by Rebecca Simon( Hightower, 2020), Extension an associate in the extension programme of the University of Arkansas. Simon and her husband operate a farm apart from their job. They said that some of the pressures coming in farming were beyond immediate control. In such situations, how one responds to stress is important. Unpredictable market conditions can increase stress on family and farm finances. These stresses can ripple into other areas of life such as making conflict within families, customers, friends and vendors. Simon worked across the state of Arkansas and helped farm families understand the factors responsible for stress and used the "Managing Rural Stress Model." This model helped 


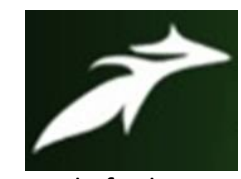

Chitrasena Padhy et al, International Journal of Advances in Agricultural Science and Technology, Vol.7 Issue.12, December-2020, pg. 110-115

ISSN: 2348-1358

Impact Factor: 6.057

NAAS Rating: 3.77

farmers to understand the different stressors that affect them and strategies to manage them effectively. The five steps of the model were assessing needs and impacts, identifying and accessing resources, pursuing good quality decisions, connecting with sources of support and using effective coping strategy. Simon suggested simple steps for coping stress can include shifting focus from worrying to problem solving, paying attention to the things accomplished rather than things unfinished, and setting realistic goals and expectations daily( Hightower, 2020).

\section{Causes of stress among farmers}

Farmers have to deal with uncertainty, financial issues, irregular weather pattern, increased regulation, animal diseases, marketing of produce, work place isolation, family expectations and succession planning, lack of respite from work. Some common symptoms of stress and poor mental health are low mood, anxiety, disturbed sleep patterns, changes in appetite, reliance on alcohol, lack of energy, lack of interest in family and friends, unable to enjoy hobbies as before, .loss of sex drive, poor concentration, confused thinkin, difficulty in taking decisions, change in personality, negative thoughts(Yanahelp, 2020).

\section{Types of Mental Health Issues}

The types of stress as described by Trillium Mutual Insurance (2020) are given below.

(i) Stress: It is the body's natural reaction to a situation that is uncomfortable. If it is not managed properly, one's level of stress can build up.

(ii) Anxiety and Panic Disorders: These are triggered by individual experience or events. Individuals experiencing this will constantly worry about a number of everyday situations. This excessive worry can lead to difficulty in concentration, irritability and restless sleep.

(iii) Depression: If depression is left untreated, it can lead to suppressed or heightened appetite, too little or too much sleep, feelings of guilt, and difficulty in concentration.

A survey of dairy farmers conducted by Teagasc, National University of Ireland Galway(NUIG) \& University of Limerick(UL), some particular mental health risk factors were associated with farming(Connolly, 2020). According to Teagasac, mental distress can arise from ongoing work, bureaucracy, time pressure, financial pressure, work unpredictability and weather uncertainty. Juggling of such competing demands can lead to poor mental health. Physically, emotionally, behaviourally and cognitively compromised mental health can manifest in number of ways. Farmers should be aware of physical symptoms such as headaches, chronic tiredness and fatigue, musculoskeletal aches and pains, hypertension, rapid heart rate, panic attacks. Emotional symptoms may include anxiety, depression, worry, feeling of powerlessness, worry, feeling trapped, frustrated, irritated, loneliness, grief and feeling like crying a lot. Cognitive symptoms may include obsessive thinking, negative thinking, poor short term memory, difficulty in concentration, mind reading, black and white thinking, interpreting things as all good or bad, and unable to see options. Behavioural symptoms may include becoming angry with other people, expressions of anger, unable to take decisions, withdrawal from family and friends, lack of self care, compulsive behaviours such as change in eating patterns, alcohol and caffeine consumption, gambling and other addictions(Connolly, 2020).

Farmers should maintain social contact, regular physical exercises, social activities and involve in fun and frolic for reducing stress (Padhy et al., 2020). 


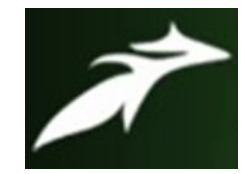

Chitrasena Padhy et al, International Journal of Advances in Agricultural Science and Technology,

Vol.7 Issue.12, December-2020, pg. 110-115

ISSN: 2348-1358

Impact Factor: 6.057

NAAS Rating: 3.77

\section{Strategies to Manage Stress}

Some unhealthy ways of coping with stress are smoking, drinking too much alcohol, zoning out in front of computer or television for too long, withdrawal from family, friends, and activities, using drugs or pills to relax, sleeping too much, overeating or under eating, talking out the stress on others. These may temporarily reduce stress but in the long run can cause damage. Robinson et al., (2018) suggested several strategies to combat stress:

\section{Strategy 1: Avoid unnecessary stress}

All stress cannot be avoided. It is not a healthy way to avoid a situation which needs to be addressed.

(i)Learn how to say "no": One should know one's limits and stick to them. One should know refusing to accept the added responsibilities when these are not reachable. Taking the responsibility beyond one's capacity is a surefire recipe for stress.

(ii) Avoiding people who cause stress: If someone is causing continuous stress in one's life, it is better to limit the timing of interaction with that person or end the relationship.

(iii) Take control of the environment: If the evening news makes one anxious, it is better to turn the TV off. If going to market causes unpleasant chore, one should do online shopping.

(iv) Avoid hot-button topics: If one gets upset over religion or politics, one should avoid them from the conversation list. Instead of repeatedly arguing about the same subject with the same people one should stop bringing up the subject.

(v) Pare down to-do list: One should analyse one's schedule, responsibilities, and daily tasks. If some tasks are not truly necessary, these should be eliminated from the list.

\section{Strategy 2; Alter the situation}

(1) Expressing feelings instead of bottling up: If bothered by someone, it is better to express one's feelings in respectful way, otherwise resentment will be built and the situation will remain the same.

(2) Be willing to compromise: One should be willing to compromise. If both parties are willing to bend a bit, there is chance of a happy middle ground.

(3) Be more assertive: One should not take a backseat in his own life. It is important to deal with problems hand on, doing best to anticipate and prevent them. For instance, If one's examination is there and his chatty roommate just got home, he should tell that he has only five minutes to talk.

(4)Manage your time better: A lot of stress can be caused by poor time management. If one is stretched too thin and running behind, it is difficult to stay calm and focused. But planning ahead is important to alter the amount of stress one has. 


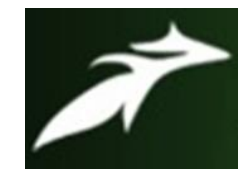

Chitrasena Padhy et al, International Journal of Advances in Agricultural Science and Technology,

Vol.7 Issue.12, December-2020, pg. 110-115

ISSN: 2348-1358

Impact Factor: 6.057

NAAS Rating: 3.77

\section{Strategy 3: Adapt to the stressor}

(1)Changing self: If one can not the change the stressor. By changing expectations and attitudes, one can adapt to stressful situations and regain the sense of control.

(2) Reframe Problems: It is important to view stressful situations from positive point of view, listen to favourite radio station or enjoy some alone time.

(3) Look at the big picture: One should pause, take perspective of the stressful situations and then react to it in a positive manner.

(4) Adjust your standards: One should set reasonable standard for himself and others. One should lower one's standards and expectations, if the high standards are causing stress.

(5) Focus on the positive: Upon feeling low and dejected, one should concentrate on positive qualities and natural gifts that they possess and reflect on all the things that can be appreciated in their lives

(6) Adjusting attitude: It is important to see the good things about oneself to feel good,

\section{Strategy 4: Accept the things you cannot change}

Stressors which are unavoidable need to be accepted as they are.

(1) Do not try to control the uncontrollable: Many things in our lives are beyond our control. There are some things beyond our control for example the behavior of other people. It is better to focus on the things that can be controlled by choosing a way to react to a problem.

(2) Look for the upside: When major challenges arise, these should be looked as opportunities for personal growth. Learning from mistakes is essential.

(3) Share feelings: Talking to a trusted friend and one's feelings helps to relieve stress.

(4) Learn to forgive: Forgiving others helps win friends and relieves stress.

\section{Strategy 5: Make time for fun and relaxation}

Some common stress management strategies are going for a walk, spending time with family, calling a dear friend, and doing a good workout. Writing for a journal, taking a long bath, playing with a pet, working in the garden, listening to music, and watching a comedy show are other ways of overcoming stress.

\section{Five ways to well-being}

Teagasc(2020) mentions 'Five Ways to Wellbeing'" to combat the mental health problems in farming community(Connolly, 2020). 


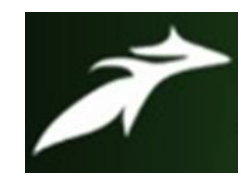

Chitrasena Padhy et al, International Journal of Advances in Agricultural Science and Technology,

Vol.7 Issue.12, December-2020, pg. 110-115

ISSN: 2348-1358

Impact Factor: 6.057

NAAS Rating: 3.77

\section{(1) Get connected:}

Feeling close to other people and valued by others contribute to well-being. Instead of sending Facabook message, or Snapchat, directly talk with someone.

\section{(2) Take notice:}

Being sensitive and aware of the people around and. enjoying and savouring the moment enhances the well-being.

\section{(3) Be active:}

Daily physical activity and regular exercises are necessary for being fit

\section{(4) Keep learning:}

Learning enhances one's self-esteem. It encourages social interaction and higher level of well-being. Finding a new hobby or interest also enhances well-being.

\section{(5) Give:}

Giving time to a voluntary organization, showing kindness, and doing good deeds for someone increases one's happiness and well-being.

\section{Conclusion}

'Managing Rural Stress Model' is a process that can help to manage the pressures that impact family, farming operations, and personal life. This process was designed to learn about different stressors and provides strategies to manage them effectively. The five steps under this model are assessing needs and impacts, identifying and accessing resources, making good quality decisions, connecting with sources of support, and using effective coping strategies. Proper rest and renewing self, healthy communication by willingness to talk, listen, and share with others, avoiding withdrawal or anger, focusing on relationships by reassuring family members of love and commitment, and following consistent family routines, for example taking family meals together, help farmers to cope with stress (Simon, 2020). Agribusiness professionals should provide key information and assist agricultural safety and health professionals in know the mental health issues of farmers and play an active role in mental health promotion (Rudolphi et al., 2020).

\section{References}

[1]. Braverma B, 2019, The 10 most dangerous jobs in America, https://www.cnbc.com/2019/12/27/the-10most-dangerous-jobs-in-america-according-to-bls-data.html

[2]. Connolly, E. (2020), Mental health risks most associated with farming, https://www.southernstar.ie/farming/mental-health-risks-most-associated-with-farming-4202631

[3]. Hightower, M. (2020), Extension Specialist helps farmers in state deal with stress, https://www.arkansasonline.com/news/2020/nov/29/extension-specialist-helps-farmers-in-state-deal/

[4]. Padhy C., Raju P. S. \& Pattanayak K. P. ,(2020), Assessment of Mental Health and Psychological Counseling for farmers, International Journal of Advances in Agricultural Science and Technology, Vol.7 Issue.11, November-2020, pg. 55-59. 


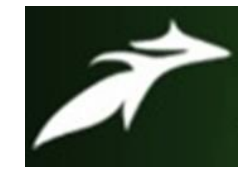

Chitrasena Padhy et al, International Journal of Advances in Agricultural Science and Technology,

Vol.7 Issue.12, December-2020, pg. 110-115

ISSN: 2348-1358

Impact Factor: 6.057

NAAS Rating: 3.77

[5]. Robinson L., Smith M, M.A. \& Segal R., M.A., (2018), Stress Management: How to Reduce, Prevent and Cope with Stress, https://www.brainline.org/article/stress-management-how-reduce-prevent-and-copestress.

[6]. Rudolphi, J.M.,\&. Barnes, K. L. (2020) Farmers' Mental Health: Perceptions from a Farm Show, Journal of Agromedicine, 25:1, 147-152, DOI: 10.1080/1059924X.2019.1674230

[7]. Simon, R., 2020, Farmers and stress: COVID-19 adds fuel to the fire, https://www.uaex.edu/life-skillswellness/health/covid19/farmers-and-stress.aspx

[8]. Teagasc, 2020, https://www.southernstar.ie/farming/mental-health-risks-most-associated-with-farming4202631

[9]. Trillium mutual insurance company (2020), The stigma surrounding mental health and the farming community, https://trilliummutual.com/blog/mental-health-and-the-farming-community/

[10]. Yanahelp, 2020, The pressures of farming and working in rural businesses, https://www.yanahelp.org/causes-and-symptoms/ 